Check for updates

Cite this: RSC Adv., 2018, 8, 2996

Received 6th September 2017 Accepted 9th January 2018

DOI: 10.1039/c7ra09952e

rsc.li/rsc-advances

\section{Development of hydrolysed protein-based plywood adhesive from slaughterhouse waste: effect of chemical modification of hydrolysed protein on moisture resistance of formulated adhesives $\uparrow$}

\author{
Birendra B. Adhikari, (DD a Vadim Kislitsin, ${ }^{\mathrm{b}}$ Pooran Appadu, ${ }^{a}$ Michael Chae, ${ }^{a}$ \\ Phillip Choi ${ }^{\mathrm{b}}$ and David C. Bressler ${ }^{\star a}$
}

Specified risk materials (SRM) constitute the proteinaceous waste of slaughterhouses and are currently being disposed off either by incineration or by land filling. Over the last few years, our efforts have focused on developing technology platforms for deployment of this renewable resource for various value-added industrial applications. This report describes a technology for utilization of SRM for the development of an environmentally friendly plywood adhesive with an improved water resistance property. The feedstock (SRM) was first thermally hydrolysed according to a standard protocol, and the hydrolysed protein fragments (peptides) were recovered from the hydrolysate. The recovered peptides were chemically modified through esterification reaction using ethanol, and then chemically crosslinked with polyamideamine-epichlorohydrin (PAE) resin to develop a wood adhesive system. Plywood specimens were then developed using the peptides-PAE resin-based adhesive. The effects of crosslinking time, solid content of the adhesive formulation, ratio of peptides and crosslinking agent in the formulation, and curing conditions of specimen preparation on lap shear strength of resulting plywood specimens were systematically evaluated. Despite the hydrophilic nature of hydrolysed protein fragments, the peptides-PAE resin formulations exhibited remarkable water resistance property after curing. Capping of polar carboxyl groups of peptides by converting them to esters further improved the water resistance property of this adhesive system. Under the optimum conditions of adhesive preparation and curing, the ethyl ester derivative of peptides and PAE resin-based formulations resulted in plywood specimens having comparable dry as well as soaked shear strengths to those of commercial phenol formaldehyde resin.

\section{Introduction}

Industrial processing of agricultural and animal products generates a significant amount of agro-industrial residues, which are composed of compounds of great industrial interest such as sugars, fibres, and proteins. Over the years, the interest in chemical conversion of waste biomass to valuable products has risen sharply as this approach has shown tremendous potential for recovering a wide range of value-added products from bio-waste. Development of sustainable technology

${ }^{a}$ Department of Agricultural, Food and Nutritional Science Faculty of Agricultural, Life and Environmental Sciences, University of Alberta, Edmonton, AB, T6G 2P5, Canada. E-mail: dbressle@ualberta.ca; Fax: +1-780-492-4265; Tel: +1-780-492-4986

${ }^{b}$ Department of Chemical and Materials Engineering Faculty of Engineering, University of Alberta, Edmonton, AB, T6G 1H9, Canada

$\dagger$ Electronic supplementary information (ESI) available. See DOI: 10.1039/c7ra09952e platforms for efficient utilization of such bio-wastes as renewable resources of energy and materials helps address the pressing issues related to depleting resources, energy, and the environment. Consequently, the concept of discovering environmentally benign and innovative ways for processing and converting biomass to value-added products is of great importance, and has emerged as an integral part of the holistic approach of sustainable development.

Of the various agro-industrial sectors producing substantial amount of bio-waste, the meat industry produces considerable amounts of proteinaceous waste from animal slaughtering and processing of meat. This proteinaceous waste consists of animal products and by-products that are not considered edible and cannot be sold as dressed meat. ${ }^{1-3}$ One way to utilize the slaughterhouse waste is processing of the waste through renderers into sellable by-products such as proteinaceous meals. ${ }^{4,5}$ However, specified risk materials (SRM) are a type of slaughterhouse waste that cannot enter the feed and food 
chain, and require segregation, removal, and disposal. These are the tissues of bovine, ovine, and caprine animals where an abnormal form of protein (called prion protein) are likely to concentrate, and these prion proteins are believed to cause a neurodegenerative disease called Bovine Spongiform Encephalopathy (BSE) or "mad cow disease" in cattle, and equivalent diseases in ovine and caprine animals, as well as in humans..$^{6-9}$ Due to the fear of potential BSE infectivity, the Canadian Food Inspection Agency (CFIA) has imposed an enhanced feed ban that precludes SRM and any tissues that come in contact with SRM from all animal feed, pet food and fertilizer applications. ${ }^{6}$ Similarly, the United States Food and Drug Administration (FDA) prohibits the use of SRM tissues in human food, dietary supplements, and cosmetics. ${ }^{10}$ Legislation from the European Food Safety Authority (EFSA) requires the segregation and removal of SRM from cattle, sheep, and goats so that these tissues do not enter the feed and food chain. ${ }^{9}$ These enhanced feed bans have led to the generation of significant amount of proteinaceous waste around the world that is being disposed off either by incineration or landfilling with considerable economic burden to meat industry as well as environmental impact. ${ }^{11}$

The CFIA and FDA recommended methods of SRM disposal include landfilling, incineration, composting, burial, and thermal or alkaline hydrolysis., ${ }^{711}$ Of these, thermal or alkaline hydrolysis is attractive as this method allows recovery of hydrolysed protein fragments from the hydrolysate, which then can be utilized in various value-added applications. For instance, protein recovered from SRM hydrolysates has shown great promise for development of bio-composites, ${ }^{12}$ bio-plastics, ${ }^{13}$ and as an adhesive for oriented strand boards ${ }^{14}$ and plywood. ${ }^{15}$

Since the international agency for research on cancer (IARC) has identified formaldehyde as a carcinogen,${ }^{16}$ there are several health and environmental concerns with the use of formaldehyde-based resins for production of engineered wood products. Nevertheless, a recent market research report revealed that urea-formaldehyde and melamine-urea-formaldehyde resins accounted for over $70 \%$ of total volume (1.96 million tons) of wood adhesive consumed in $2015 .{ }^{17}$ As a potential alternative to such formaldehyde-based adhesives, there has been growing interest in development of protein-based wood adhesives. ${ }^{17,18}$ Even though the protein-based adhesives offer environmental benefits over petrochemical-based products, one of the major issues concerning the use of protein-based adhesives in engineered wood products is poor moisture resistance, which makes these renewable resource-based products less attractive for real time applications. The adhesives developed from proteinaceous material recovered from SRM also exhibited promising adhesive properties under dry conditions, but the resulting wood composites had limited moisture resistance. ${ }^{14,15}$

Review of literature on current trends of protein-based adhesive formulations from various protein sources indicates that the approaches of chemical modification of protein or chemical crosslinking of protein with suitable crosslinking agent and/or combination thereof have resulted in proteinbased wood adhesive formulations demonstrating enhanced adhesive strength as well as moisture resistance, with some formulations satisfying the performance requirements of the American Society for Testing and Materials (ASTM) and International Organization for Standardisation (ISO). ${ }^{19}$ The multifunctional compounds possessing reactive sites that are prone to react with the functional groups such as amine, hydroxyl, and carboxyl of protein and/or peptides are effective protein crosslinking reagents, and have shown great promise as crosslinking agents for formulation of protein-based adhesive systems for wood bonding applications. ${ }^{14,19-22}$

The polyamideamine epichlorohydrin (PAE) resins are such polymeric resins that contain reactive sites susceptible to react with nucleophilic groups such as amine, hydroxyl, and carboxyl groups. ${ }^{23}$ Because of the potentiality of these resins to react with such functional groups, the PAE resins are widely used as commercial wet strength additive in manufacturing of wet strength papers. ${ }^{24,25}$ Kymene $^{\mathrm{TM}} 557 \mathrm{H}$, a representative PAE resin, has also shown promise as a crosslinking agent for adhesive development from soy protein isolate. ${ }^{20,22}$ Recently, we reported on wood adhesive potential of SRM hydrolysates after crosslinking with PAE resin. ${ }^{26}$ In a continuation of our research aimed to develop an environmentally sound plywood adhesive that incorporates protein sourced from SRM and meets the industry requirements, we report on the effect of chemical modification of SRM hydrolysates on the water resistance property of the formulated adhesive.

\section{Experimental}

\subsection{Instrumentation}

Thermal hydrolysis of SRM was performed using a $5.5 \mathrm{~L}$ high temperature and high pressure stainless steel Parr reactor vessel (Parr 4582) equipped with Parr reactor controller (Parr 4848, Parr Instrument Company, Moline, IL, USA). Size exclusion high performance liquid chromatography (SEC-HPLC) analysis of hydrolysed protein was conducted using an Agilent Technologies 1200 series HPLC (Agilent Technologies, Santa Clara, CA, USA) equipped with an autosampler, variable wavelength UV detector, and two size exclusion columns - Superdex ${ }^{\mathrm{TM}} 200$ and Superdex $^{\mathrm{TM}}$ peptide (GE Healthcare Biosciences AB, Uppsala, Sweden). Viscosity of adhesive formulations was measured using an OFITE model 900 viscometer (OFI Testing Equipment, Houston, TX, USA). Hot pressing of plywood specimens was performed using a Carver hot press (Model 3890 Auto 'M', Carver Inc., Wabash, IN, USA). A CMP 6050 plant growth chamber (Conviron, Winnipeg, $\mathrm{MB}$, Canada) was used for conditioning of plywood specimens prior to testing. The plywood specimens were tested using mechanical test system (MTS 810, MTS Systems Corporation, Eden Prairie, MN, USA) equipped with a $10 \mathrm{kN}$ load cell. The scanning electron microscope (SEM) images of wood specimens were acquired using Zeiss Sigma 300 VP Field Emission SEM (Carl Zeiss AG, Oberkochen, Germany) operating at $20 \mathrm{kV}$.

\subsection{Materials and chemicals}

The feedstock (SRM) was supplied in dried, ground form, and was handled following the CFIA recommended protocol for safe handling and disinfection of SRM. ${ }^{27} \mathrm{Kymene}^{\mathrm{TM}}$ 557H resin from 
Solenis (Wilmington, DE, USA) was used as a representative PAE resin. The phenol formaldehyde (PF) resin was generously provided by a commercial supplier located in Edmonton, AB, Canada. According to the information provided by respective suppliers, the PAE and PF resins contained $12.5 \%$ and $43 \%$ solids, respectively. The poplar veneers used in this study were of $1.6 \mathrm{~mm}$ thickness, and were purchased from a local supplier. Solvents and all other chemicals used in this study were of ACS grade, and were acquired from Fisher Scientific (Fair Lawn, NJ, USA).

\subsection{Methods}

2.3.1. Thermal hydrolysis of SRM and recovery and characterization of peptides. The Canadian Food Inspection Agency (CFIA) approved protocol for thermal hydrolysis of SRM requires a temperature of $\geq 180{ }^{\circ} \mathrm{C}$ and pressure of $\geq 1200 \mathrm{kPa}$ for 40 min per cycle. ${ }^{7}$ Following these CFIA guidelines, we have developed and optimized the conditions for thermal hydrolysis of $\mathrm{SRM},{ }^{27}$ and the previously optimized conditions $\left(180{ }^{\circ} \mathrm{C}\right.$, $\geq 174$ psi, 40 minutes) were used for conducting thermal hydrolysis of SRM in this study. Before hydrolysis, the SRM sample was handled as a potential biohazard and all the safety measures were practiced as described in previous reports. ${ }^{26,27}$ Recovery of hydrolysed protein from the post hydrolysis material was also achieved by following our standard protocol published elsewhere. ${ }^{15,26}$ The hydrolysed protein fragments (referred to as peptides hereafter) were recovered on average of $35 \pm 1 \%$ of the feedstock.

In order to ensure batch-to-batch reproducibility, thermal hydrolysis was done in at least three replicates, and the recovered peptides were characterised by following the standard characterization methods being practiced in our lab that consists of elemental analysis, analysis of end functional groups (carboxyl and amines) and analysis of molecular size distribution by SEC-HPLC. ${ }^{26,27}$ Analysed in at least three replicates, all these studies ensured batch-to-batch reproducibility of the starting material (peptides).

2.3.2. Chemical modification of peptides. The hydrolyzed peptides were chemically modified through conversion of terminal carboxyl groups to esters via esterification reaction using ethanol in presence of catalytic amount of concentrated $\mathrm{HCl}$. The esterification reactions were conducted by adopting the conditions previously reported for esterification of a number of proteins as well as polyglutamic acid, ${ }^{28}$ which was also reported to be very effective for esterification of soy protein. ${ }^{29}$ In a typical esterification reaction, a slurry of $20 \mathrm{~g}$ peptides and $400 \mathrm{~mL}$ ethanolic $\mathrm{HCl}(0.1 \mathrm{M} \mathrm{HCl}$ in ethanol) was stirred at room temperature for 48 hours (this condition was found to be the best suited condition as determined by the evaluation of extent of esterification and percentage yield of the product; details in Table 3). Afterwards, the $\mathrm{pH}$ was adjusted to 5.5 with $\mathrm{NH}_{4} \mathrm{OH}$ and the chemically modified peptides were recovered after vacuum filtration at average yields of $65 \pm 1 \%$. The percentage yield reported here is of the solid residue obtained after removal of ethanol by vacuum filtration at the end of the reaction. The chemically modified peptides are named as Et-peptides hereafter.

\subsection{Adhesive formulation}

2.4.1. General method. The adhesive formulations were prepared by mixing peptides with PAE resin followed by stirring the resulting slurry at room temperature. This stirring of the mixture allows for mixing of the components and chemical reactions to occur (if any reactions occur prior to hot pressing). Results of our previous experiments using unmodified peptides indicated that the peptides-PAE resin-based adhesive formulation containing $20 \%$ solid could be spread reasonably well, and had ability to properly wet the wood surface. ${ }^{26}$ Hence, in our preliminary investigations conducted to assess the performance of adhesive systems using Et-peptides, the total solid content of our formulation was $20 \%$. This formulation was prepared by mixing $20.0 \mathrm{~g}$ of PAE resin (total solids $=2.5 \mathrm{~g}$ ) with $2.0 \mathrm{~g}$ of Etpeptides (formulation 2, Table 1).

2.4.2. Varying the solid content of adhesive formulation. In experiments designed to assess the effect of solid content of the Et-peptides-PAE resin on lap shear strength of resulting plywood specimens, the solid content of adhesive formulations varied from 15 to $35 \%$ on dry weight basis (Table 1). The formulation containing $40 \%$ solids was highly viscous and could not be spread smoothly on the wood surface, and thus was not considered for further studies.

2.4.3. Varying the ratio of peptides and PAE resin. The effect of the ratio of Et-peptides and PAE resin of our formulations on lap shear strength of resulting plywood specimens was explored by varying the amounts of PAE resin and Et-peptides in the mixture as shown in Table 2. The total solid content of these formulations was $20 \%$, and the weight percentage of the crosslinking agent varied from zero (peptides only) to $55 \%$.

\subsection{Preparation of plywood specimens}

The plywood specimens were prepared using poplar veneer of $1.6 \mathrm{~mm}$ thickness. The veneer sheets were cut into rectangular panels $(50 \times 20 \mathrm{~mm})$, and the panels were pre-conditioned in a growth chamber maintained at $70 \%$ relative humidity so as to allow the panels to reach a moisture content of 10-12\% (ASTM D2339-98). The adhesive slurry (3.0 $\mathrm{mg} \mathrm{cm}^{-2}$ adhesive on dry weight basis) was then coated on $20 \mathrm{~mm} \times 20 \mathrm{~mm}$ area of each panel in such a way that it properly wets the entire surface. The adhesive coated panels were then assembled (grains being in parallel direction), and allowed to equilibrate for 10 minutes to allow the adhesive to penetrate into the wood. The assembled pieces were then subjected to hot pressing for five minutes at various temperature/pressure combinations.

\subsection{Testing of plywood specimens}

The effectiveness of adhesive formulations as plywood adhesive was then assessed by evaluating the lap shear strength of plywood specimens according to ASTM standard method (ASTM D2339-98) using a mechanical test system (MTS) equipped with $10 \mathrm{kN}$ load cell. While testing the specimens, the MTS was operated at a crosshead speed of $1 \mathrm{~mm} \mathrm{~min}^{-1}$ so that the axial load was in the range of 4535 to $7560 \mathrm{~g} \mathrm{~s}^{-1}$ (ASTM D2339-98). The test specimens loaded on MTS were pulled apart from 
Table 1 Formulations of Et-peptides-PAE resin adhesive developed by varying the solid content of the formulation

\begin{tabular}{|c|c|c|c|c|c|c|}
\hline Formulation & PAE resin $(\mathrm{g})$ & $\begin{array}{l}\text { Peptides } \\
\text { (g) }\end{array}$ & $\begin{array}{l}\text { Total amount } \\
(\mathrm{g})\end{array}$ & $\begin{array}{l}\text { Solid from PAE resin, } \\
\text { dry basis }(\mathrm{g})\end{array}$ & $\begin{array}{l}\text { Total solid } \\
(\mathrm{g})\end{array}$ & $\begin{array}{l}\text { Solid content } \\
(\%)\end{array}$ \\
\hline 1 & 20 & 0.6 & 20.6 & 2.5 & 3.1 & 15 \\
\hline 3 & 20 & 3.3 & 23.3 & 2.5 & 5.8 & 25 \\
\hline 4 & 20 & 5.0 & 25.0 & 2.5 & 7.5 & 30 \\
\hline 5 & 20 & 7.0 & 27.0 & 2.5 & 9.5 & 35 \\
\hline
\end{tabular}

Table 2 Formulations of Et-peptides-PAE resin adhesive developed by varying the ratio of peptides and PAE resin

\begin{tabular}{|c|c|c|c|c|c|c|c|c|}
\hline Formulation & $\begin{array}{l}\text { PAE resin } \\
(\mathrm{g})\end{array}$ & $\begin{array}{l}\text { Peptides } \\
\text { (g) }\end{array}$ & $\begin{array}{l}\text { Water } \\
(\mathrm{g})\end{array}$ & $\begin{array}{l}\text { Total amount } \\
(\mathrm{g})\end{array}$ & $\begin{array}{l}\text { Solid from PAE } \\
\text { resin, dry basis (g) }\end{array}$ & $\begin{array}{l}\text { Total solid } \\
(\mathrm{g})\end{array}$ & $\begin{array}{l}\text { Solid content } \\
(\%)\end{array}$ & $\begin{array}{l}\mathrm{Wt} \% \text { of PAE } \\
\text { resin (dry basis) }\end{array}$ \\
\hline 1 & 0.0 & 4.5 & 17.5 & 22.0 & 0.00 & 4.5 & 20 & 0 \\
\hline 3 & 4.0 & 4.0 & 14.0 & 22.0 & 0.50 & 4.5 & 20 & 11 \\
\hline 4 & 8.0 & 3.5 & 10.5 & 22.0 & 1.00 & 4.5 & 20 & 22 \\
\hline 5 & 12.0 & 3.0 & 7.0 & 22.0 & 1.50 & 4.5 & 20 & 33 \\
\hline
\end{tabular}

two edges until they underwent lap shear. The force (in N) at which the specimens undergo lap shear is expressed as lap shear strength (MPa) after dividing the force $(\mathrm{N})$ by the glued area $\left(\mathrm{mm}^{2}\right)$.

The lap shear strengths of plywood specimens were assessed under dry, soaked, and wet conditions. The dry shear strength was evaluated according to ASTM standard method (ASTM D2339-98) in which the hot pressed plywood specimens were conditioned at $23{ }^{\circ} \mathrm{C}$ and $50 \%$ relative humidity for 7 days prior to testing. The effect of moisture on adhesive bond was assessed by evaluating soaked and wet shear strengths of plywood specimens.

In soaked shear strength analysis, the bonded specimens were immersed in water (at $23^{\circ} \mathrm{C}$ ) for 48 hours (ASTM D1183-03, test designation C) followed by conditioning the specimens for 7 days at $23{ }^{\circ} \mathrm{C}$ and $50 \%$ relative humidity before evaluating the lap shear strength (ASTM D2339-98 and ASTM D1151-00). The wet shear strength of plywood specimens was evaluated as described by Wang et $a .^{30}$ in accordance to ASTM method for testing the effect of moisture on adhesive bonds (ASTM D1151$00)$. In wet shear strength analysis, the plywood specimens were immersed in water at $23{ }^{\circ} \mathrm{C}$ for $48 \mathrm{~h}$, and the lap shear strength was analyzed immediately after the specimens were removed from the water bath. A summary of preparation and testing of plywood specimens is presented in Scheme 1. In testing of each formulation and/or condition, the data points were obtained from the analysis of six specimens, and the results are presented as mean \pm standard deviation. Significant differences
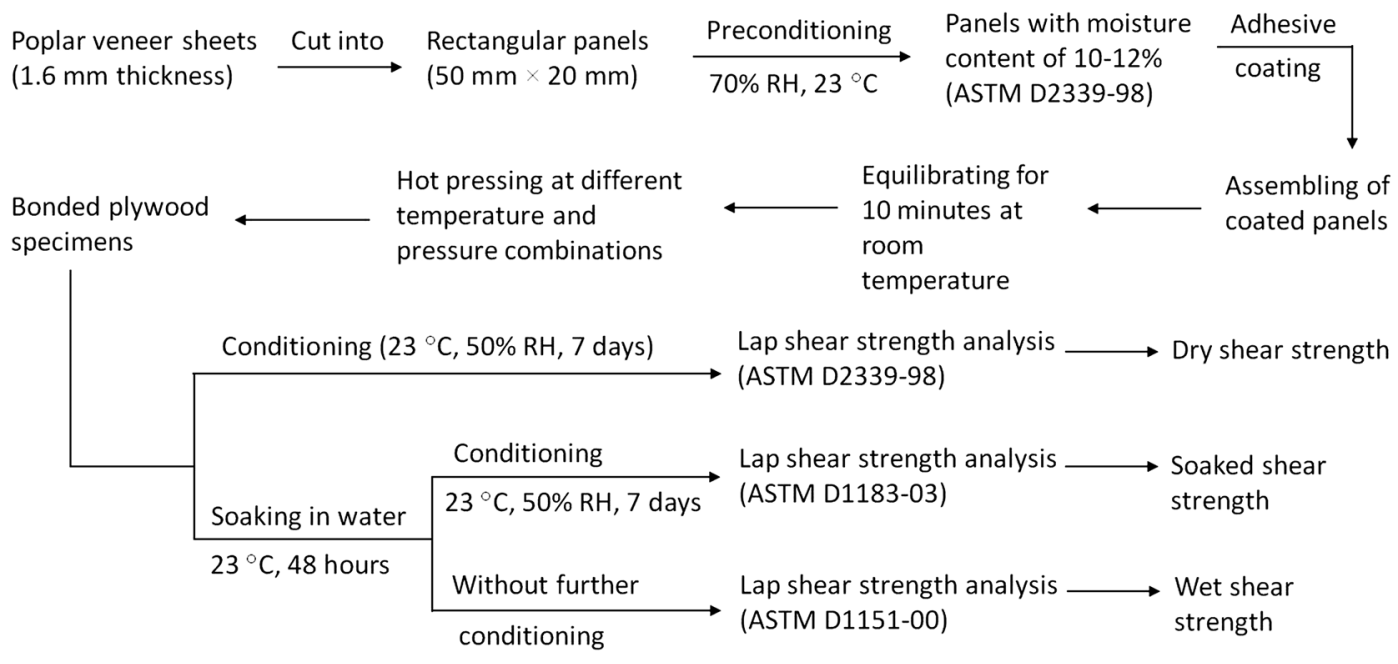

Scheme 1 Preparation and lap shear strength analysis of plywood specimens. 
between the formulations (data points) were determined by the Tukey test using minitab17 with 95\% confidence limit.

\section{Results and discussion}

\subsection{Chemical modification of peptides}

As thermal hydrolysis of protein results in increased hydrophilicity as a result of reduced molecular weight of polypeptides and increase in terminal hydrophilic groups, the peptides recovered from SRM hydrolysate are inherently hydrophilic in nature. Consequently, low water resistance of bonded wood specimens is the major issue concerning the use of SRM hydrolysates in adhesive formulations. ${ }^{\mathbf{4}, 15}$ Capping polar carboxyl groups by converting them to esters is one way to enhance the hydrophobic nature of proteins and/or peptides. Fortunately, esterification of proteins with low molecular weight primary alcohols can be achieved simply by stirring the suspension of the protein in an appropriate alcohol and in the presence of catalytic amounts of $\mathrm{HCl}$ at room temperature. ${ }^{28,29}$ Hence, the peptides recovered from SRM hydrolysate were converted to ethyl ester derivative, and its adhesive formulations with PAE resin were developed to investigate the effect of chemical modification of peptides on lap shear strength of plywood specimens.

The carboxyl groups content of peptides before and after esterification reactions was determined by $\mathrm{pH}$ titration as described previously, ${ }^{26}$ and the extent of esterification was assessed from the differences in carboxyl groups before and after the reaction. The effects of ratio of peptides and alcohol, stirring time, and concentration of $\mathrm{HCl}$ on extent of esterification of peptides with ethanol were examined (Table 3). Our results indicated that $1: 20(\mathrm{wt} / \mathrm{vol})$ ratio of peptides : alcohol, and stirring time of 48 hours using $\mathrm{HCl}$ in $0.1 \mathrm{M}$ concentration in ethanol were the best suited conditions for preparation of ethyl ester derivative of peptides.

\subsection{Adhesive performance of Et-peptides-PAE resin formulations}

Curing of adhesives is an essential step of plywood manufacturing that is achieved by subjecting the glued veneer sheets to heat and pressure in a hot press. The hot press temperature in commercial production of wood composites is in the range of $120-160^{\circ} \mathrm{C}^{.21}$ In the plywood industry, the typical press temperature ranges from 107 to $135{ }^{\circ} \mathrm{C}$ for hardwood plywood and from 132 to $165^{\circ} \mathrm{C}$ for softwood plywood. ${ }^{31}$ Review of the literature suggests that the pressure used for hot pressing of glued specimens bonded with protein-based adhesives ranges from 2 to $5 \mathrm{MPa}$, and the pressing time ranges from 3 to 10 minutes. $^{30,32,33}$ For peptides-PAE adhesive system using unmodified peptides, the curing condition of $120{ }^{\circ} \mathrm{C}$ and 3.5 $\mathrm{MPa}$ pressure for 5 minutes resulted in strong adhesive bonding. ${ }^{26}$ Adopting such conditions for hot pressing, we first analysed the lap shear strength of plywood specimens bonded with Et-peptides-PAE resin formulation as well as the individual components of this formulation - Et-peptides and PAE resin (Fig. 1).

The plywood specimens bonded with Et-peptides alone had an average dry shear strength of $0.97 \pm 0.53 \mathrm{MPa}$, and all the test samples displayed adhesive failure during testing. Entanglements and/or crosslinks among the polymer chains determine the forces of cohesion and adhesion, and these forces play an important role in determining the overall adhesive strength of any adhesive system. ${ }^{34-37}$ Hence, the poor performance of Etpeptides is likely attributable to the lack of molecular entanglements and lower cohesive strength within the adhesive. The hydrolysed peptides are relatively low molecular weight short chain polymers with very little or no entanglements of polymer chains. This translates to lower cohesive strength within the bulk of the adhesive resulting in adhesive failure of test specimens. Additionally, all the test specimens prepared using Etpeptides alone were delaminated when immersed in water (Fig. 1) indicating a very poor water resistance of this adhesive system, which also originates from the hydrophilic nature of peptides and lack of crosslinks among the polymer chains.

The adhesive formulation prepared by stirring the mixture of Et-peptides and PAE resin ( $1: 1.25$ on dry weight basis) for 2 hours at room temperature yielded plywood specimens that had an average lap shear strength of $4.89 \pm 0.54$ and $4.23 \pm$ 0.44 MPa under dry and soaked conditions, respectively (Fig. 1). The observed notable enhancement in lap shear strength of

Table 3 Extent of esterification of SRM hydrolysates achieved under different conditions

\begin{tabular}{llll}
\hline Peptides : alcohol ratio & {$[\mathrm{HCl}]$ in ethanol (M) } & Reaction time (hrs) & Extent of esterification $^{a}(\%)$ \\
\hline $1: 20$ & 0.10 & 24 & $14.43 \pm 1.46$ \\
$1: 20$ & 0.10 & 48 & $23.10 \pm 0.52$ \\
$1: 20$ & 0.10 & 72 & $20.82 \pm 0.69$ \\
$1: 20$ & 0.10 & 96 & $18.84 \pm 0.78$ \\
$1: 20$ & 0.10 & 128 & $14.28 \pm 0.00$ \\
$1: 10$ & 0.10 & 48 & $14.43 \pm 0.26$ \\
$1: 50$ & 0.10 & 48 & $54.71 \pm 0.69^{b}$ \\
$1: 20$ & 0.05 & 48 & $14.13 \pm 1.27$ \\
$1: 20$ & 0.20 & 48 & $38.44 \pm 0.78^{c}$ \\
$1: 20$ & 0.30 & $45.28 \pm 0.91^{d}$
\end{tabular}

${ }^{a}$ The fraction of carboxyl groups converted to ester. ${ }^{b}$ Only $34 \%$ of solid residue was obtained after vacuum filtration of reaction mixture.

${ }^{c}$ Percentage of solid residue obtained after vacuum filtration was only $46 \% .{ }^{d}$ Vacuum filtration of reaction mixture afforded only $33 \%$ solid residue. 


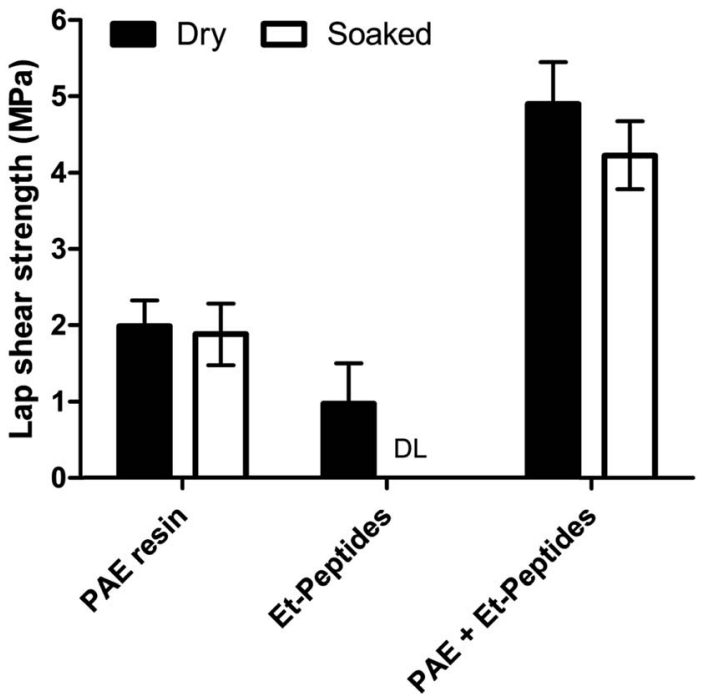

Fig. 1 Lap shear strength of plywood specimens bonded with Etpeptides, PAE resin, and PAE resin + Et-peptides-based adhesive system. The solid content for Et-peptides was 20\%. For Et-peptidesPAE formulations, $2.0 \mathrm{~g}$ of peptides were mixed with $20.0 \mathrm{~g}$ PAE resin (solid content $=20 \%$, peptides : PAE resin $=1: 1.25$ on dry weight basis) and stirred for 120 minutes at room temperature prior to coating. Specimens were hot pressed at $120^{\circ} \mathrm{C}$ and $3.5 \mathrm{MPa}$ for five minutes. Error bars indicate standard deviation of six plywood specimen measurements. DL indicates the specimens were delaminated when soaked in water.

plywood specimens bonded with Et-peptides-PAE resin adhesive is likely attributable to the effect of chemical crosslinking within the bulk of the adhesive and chemical reactions that occur between the adhesive and substrate in the curing step. Chemical crosslinking - that would take place through the reaction of amine and carboxyl functional groups of peptides with the reactive sites of PAE resin molecules in the curing stage $\mathrm{e}^{\mathbf{2 0 , 2 2}}$ - would lead to the formation of large molecular weight threedimensional rigid networks of polymers connected through covalent linkages. This phenomenon enhances the cohesive strength within the bulk of the adhesive, and also promotes entanglements of polymer chains preventing them from creeping during mechanical testing, which translates to higher lap shear strengths. Additionally, the formation of a rigid crosslinked structure improves the water resistance property of this adhesive system. Furthermore, the crosslinked product of PAE resin and Et-peptides would react with the functional groups of cellulose (wood) in curing step through the formation of water resistant covalent linkages. $^{20,22}$ Taken together, these phenomena of chemical crosslinking between the components of the adhesive system and possible chemical interactions between the adhesive and adherends in the curing step resulted in enhanced lap shear strength in dry as well as soaked conditions.

\subsection{Effect of different parameters on adhesive strength of Et-peptides-PAE resin adhesives}

The minimum shear strength requirement specifications of ASTM for urea formaldehyde (UF) resin type wood adhesives are

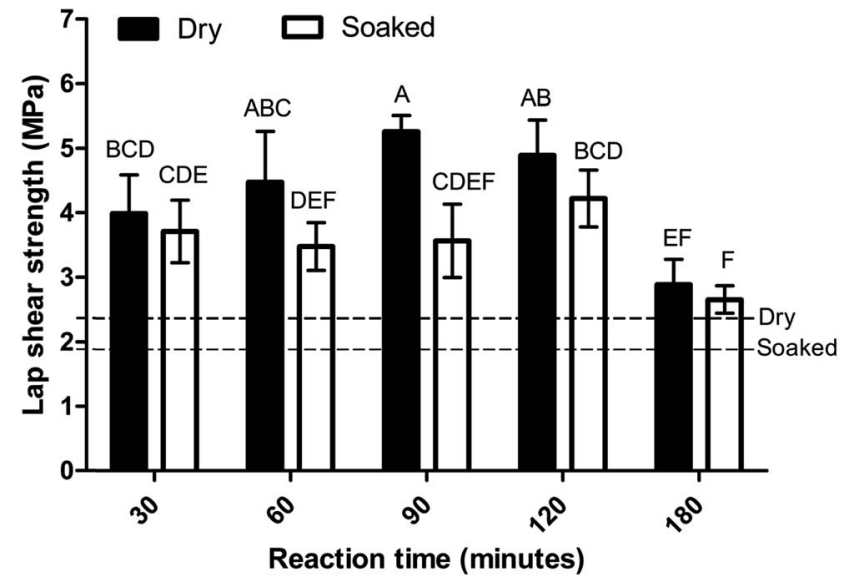

Fig. 2 Effect of reaction time of Et-peptides and PAE resin on lap shear strength of plywood specimens bonded with resulting adhesive formulations. In these formulations, $2.0 \mathrm{~g}$ of peptides were mixed with $20.0 \mathrm{~g}$ PAE resin (peptides : PAE resin $=1: 1.25$ on dry weight basis, $20 \%$ solids). Specimens were hot pressed at $120^{\circ} \mathrm{C}$ and $3.5 \mathrm{MPa}$ for five minutes. Error bars indicate standard deviation of six plywood specimen measurements. Means that do not share a letter are significantly different (Tukey, 95\% confidence level). The minimum shear strength requirements as specified by ASTM D4690 are shown: $2.344 \mathrm{MPa}$ for dry shear strength; and $1.93 \mathrm{MPa}$ for soaked shear strength.

2.344 and $1.93 \mathrm{MPa}$ under dry and soaked conditions, respectively. ${ }^{38}$ Considering these numbers as baseline for performance evaluation of Et-peptides-PAE resin adhesives, this formulation produced plywood specimens that safely passed the strength requirement for UF resin type of wood adhesives. These results imply that this adhesive has the potential to substitute for UFbased resins for wood bonding applications.

Once potential of the Et-peptides-PAE resin system for wood bonding applications was established under the conditions specified in Fig. 1, we were curious to see how different factors associated with adhesive formulation and curing influence the adhesive strength of the resulting adhesive formulation. Consequently, we evaluated the effects of (i) reaction time of Etpeptides and PAE resin prior to coating, (ii) total solid content of the adhesive formulation, (iii) ratio of peptides and PAE resin, and (iv) curing (hot pressing) conditions, on adhesive strength of this adhesive system.

3.3.1. Effect of reaction time of Et-peptides and PAE resin. The effect of reaction time of Et-peptides and PAE resin on adhesive strength was investigated by evaluating the lap shear strength of plywood specimens bonded with Et-peptides-PAE resin formulation reacted for 30, 60, 90, 120 and 180 minutes prior to hot pressing. The results of the lap shear strength analysis as a function of reaction time (Fig. 2) indicate that the reaction time of 30 minutes was sufficient to create effective crosslinking of Et-peptides and PAE resin, as indicated by the dry and soaked shear strengths observed, which were well above the ASTM standards. However, the dry shear strength of the formulation reacted for 30 minutes was statistically lower than that of the formulation reacted for 90 minutes, although there was no significant difference between the 30, 60, and 120 
Table 4 Mode of failure of plywood specimens bonded with adhesive formulations reacted for different amount of time. For each condition, six test specimens were examined

\begin{tabular}{|c|c|c|}
\hline Reaction time (minutes) & Dry samples & Soaked samples \\
\hline \multirow[t]{2}{*}{30} & Cohesive wood failure $^{a}=50 \%$ & Cohesive wood failure $=50 \%$ \\
\hline & Fibre pulled out ${ }^{b}=50 \%$ & Fibre pulled out $=50 \%$ \\
\hline & Fibre pulled out $=17 \%$ & Fibre pulled out $=67 \%$ \\
\hline \multirow[t]{2}{*}{90} & Cohesive wood failure $=83 \%$ & Cohesive wood failure $=83 \%$ \\
\hline & Fibre pulled out $=17 \%$ & Fibre pulled out $=17 \%$ \\
\hline 180 & Fibre pulled out $=50 \%$ & Fibre pulled out $=33 \%$ \\
\hline & Adhesive failure $^{c}=50 \%$ & Adhesive failure $=67 \%$ \\
\hline
\end{tabular}

${ }^{a}$ Deep wood fracture from the bondline. ${ }^{b}$ Shallow wood failure with wood fibres remaining attached to the adhesive film. ${ }^{c}$ Failure within the bulk of adhesive.

minutes systems. Conversely, there were no significant differences in soaked shear strength among the formulations reacted for 30-, 60-, 90-, and 120 minutes (Fig. 2). Additionally, the specimens bonded with formulations reacted from 30 to 120 minutes underwent either cohesive wood failure (deep wood fracture from bondline) or fiber pulling (shallow wood failure), but none of these specimens underwent failure within the bulk of adhesive (Table 4). These types of wood failure indicate that the adhesive bonding resulted from these formulations is stronger than the strength of veneer. Even though there was a significant drop in lap shear strength of plywood specimens bonded with the formulation reacted for 180 minutes, all the formulations regardless of reaction time met the minimum shear strength requirement specifications of ASTM D4690 for UF resin type wood adhesives: 2.344 MPa for dry shear strength, and 1.93 MPa for soaked shear strength.

A significant drop in performance was observed for the formulation reacted for 180 minutes (Fig. 2). Analysis of failure of test specimens indicates that the plywood specimens prepared by bonding with this particular formulation underwent either adhesive failure within the bulk of adhesive or shallow wood failure, but not deep wood fracture (Table 4; the photographs of tested specimens and SEM images of fractured wood surfaces are provided in ESI $\dagger$ ). This implies that the extent of bonding between the adhesive and the substrate in the curing step was significantly dropped when the formulation was reacted for 180 minutes prior to curing. Studies on adhesive strength of polymers have revealed that there is an optimum molecular weight of polymers at which the optimum combination of adhesive and cohesive forces is achieved that contributes to the highest shear strength. ${ }^{37,39-41}$ Since the curing condition remains same for all the formulations, the decrease in performance of the formulation reacted for 180 minutes is most likely due to the properties of uncured adhesive such as viscosity, flow property, and penetration ability.

Whilst too deep or too shallow penetrations lead to reduced bond strength, ${ }^{34,35}$ optimum penetration with a certain degree of penetration depth enhances adhesion strength of protein adhesives by developing a three-dimensional zone at the interface. ${ }^{42}$ Adhesive with very large molecular weight polymers and higher viscosity have shallower penetration from the surface of the wood, which translates to ineffective mechanical interlocking and reduced adhesive strength..$^{34,35,42}$ The properties like viscosity and penetration ability of uncured adhesive are affected by intermolecular interactions and the extent of polymer crosslinking. ${ }^{36,43}$ Based on these proven facts, the observed pattern at 180 minutes may be associated with two factors arising from extensive intermolecular interaction of Et-peptides and PAE resin molecules - (i) the extensive interaction among the polymers leading to increased molecular weight and reduced penetration ability of uncured adhesive, and (ii) the extensive intermolecular interaction leading to higher degree of crosslinking in curing step thereby making only lesser number of reactive groups available for bond formation with wood in the curing step.

In order to gain further insight into the data above, we measured the viscosity of Et-peptides-PAE resin formulations reacted for different times (Table 5). The viscosity of this formulation increases with increasing reaction time, which is indicative of an increase in molecular weight due to chemical crosslinking and increased polymer chain entanglement. ${ }^{43}$ Thus, the drop in performance of the formulation reacted for 180 minutes is likely attributable to excessive polymer crosslinking and increased viscosity of the system, both of which lead to weaker penetration and reduced bond strength.

Table 5 Viscosity of Et-peptides-PAE resin adhesive system as a function of reaction time. The solid content of the system was $20 \%$. Means that do not share a letter are significantly different (Tukey, 95\% confidence level)

\begin{tabular}{lll}
\hline Sample/formulation & Reaction time & $\begin{array}{l}\text { Viscosity (cP) at } \\
100 \mathrm{rpm} \text { shear rate }\end{array}$ \\
\hline PAE resin alone & - & $32.63 \pm 0.06$ \\
Et-peptides-PAE resin & On mixing & $41.20 \pm 0.10^{\mathrm{F}}$ \\
& 30 minutes & $44.63 \pm 0.15^{\mathrm{E}}$ \\
& 60 minutes & $45.46 \pm 0.11^{\mathrm{D}}$ \\
& 90 minutes & $46.33 \pm 0.35^{\mathrm{C}}$ \\
& 120 minutes & $47.16 \pm 0.05^{\mathrm{B}}$ \\
& 180 minutes & $48.43 \pm 0.12^{\mathrm{A}}$
\end{tabular}




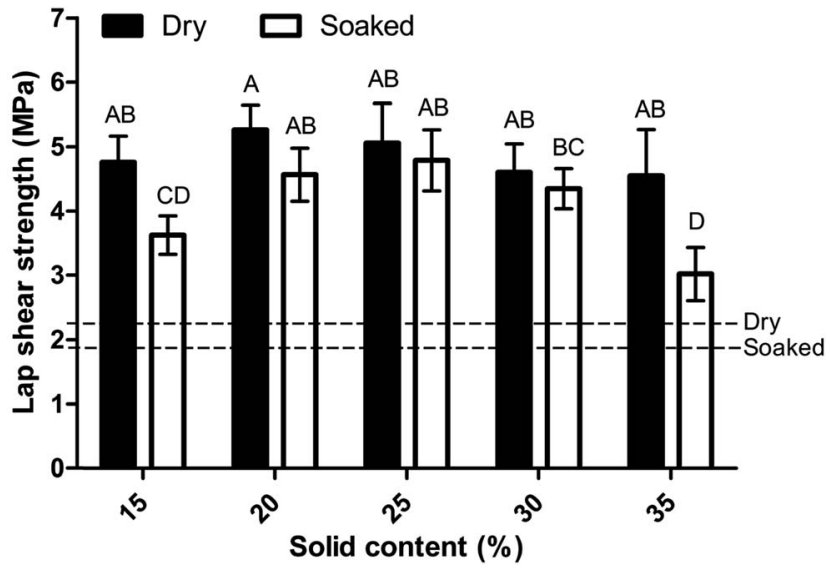

Fig. 3 Effect of the solid content of adhesive formulations on lap shear strength of plywood specimens bonded with Et-peptides-PAE adhesives. The adhesive components were reacted for 120 minutes at room temperature. Specimens were hot pressed at $120{ }^{\circ} \mathrm{C}$ and $3.5 \mathrm{MPa}$ for five minutes. Error bars indicate standard deviation of six plywood specimen measurements. Means that do not share a letter are significantly different (Tukey, 95\% confidence level). The minimum shear strength requirements as specified by ASTM D4690 are shown: $2.344 \mathrm{MPa}$ for dry shear strength; and $1.93 \mathrm{MPa}$ for soaked shear strength.

One of the requirements of commercial plywood adhesives is that they cure slowly at room temperature, allowing sufficient time for adhesive coating and assembling of wood components, but can cure quickly upon heating of the glued specimens. ${ }^{34,35}$ The results shown in Fig. 2 indicate that the Et-peptides-PAE adhesive system fulfills this requirement under the experimental conditions as described. This adhesive can be used after 30 minutes of mixing the components, and remains fully functional for up to 120 minutes without significant reduction in adhesive strength and water resistance property. As the formulation reacted for 120 minutes produced specimens with excellent dry and soaked shear strengths (that were also statistically similar to each other), this reaction time was used in further experiments examining the effects of other parameters on adhesive strength of this formulation.

3.3.2. Effect of solid content. A review of the literature indicates that the protein-based adhesive formulations investigated for making wood composites generally have a solid content of $20-35 \% .{ }^{19}$ Hence, we investigated the effect of solid content of the Et-peptides-PAE resin formulation on lap shear strength of plywood specimens in the range of 15 to $35 \%$ total solids. The specimens bonded with our formulation having 15 to $35 \%$ solids had no significant differences in dry shear strength (Fig. 3). As the strength of veneer limits the strength of adhesive, the effect of solid content of the formulation is not obvious in dry shear strength testing. The solid content of the formulations, however, exhibited a remarkable effect on soaked shear strength. The soaked shear strength of these formulations increased with solid content and then decreased, making formulations containing 15 and 35\% solids yielding significantly lower adhesive strength than those having 20, 25 and $30 \%$ solids.

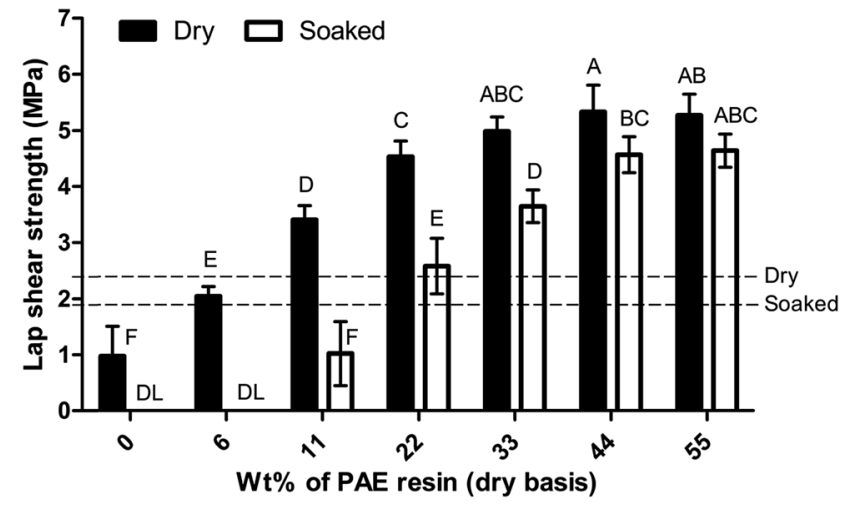

Fig. 4 Effect of Et-peptides: PAE resin ratio of adhesive formulation on lap shear strength of plywood specimens bonded with Etpeptides-PAE adhesives. The solid content of adhesive formulations was $20 \%$ and the components were reacted for 120 minutes. Specimens were hot pressed at $120{ }^{\circ} \mathrm{C}$ and $3.5 \mathrm{MPa}$ for five minutes. Error bars indicate standard deviation of six plywood specimen measurements. Means that do not share a letter are significantly different (Tukey, 95\% confidence level). The minimum shear strength requirements as specified by ASTM D4690 are shown: 2.344 MPa for dry shear strength; and $1.93 \mathrm{MPa}$ for soaked shear strength.

The ability of protein solution/dispersion to create effective mechanical interlocking by penetrating through the wood surface to an optimum depth is one of the most important factors that determine the adhesive strength of protein-based adhesive formulations. ${ }^{\mathbf{1 9 , 3 4 , 3 5 , 4 2}}$ Cheng et al. demonstrated through scanning electron microscopy (SEM) images of wood specimens coated with protein-based adhesives of different viscosities that the adhesives with different viscosity have different penetration depths into the wood surface. ${ }^{42}$ Adhesives with low solid content are generally too thin, which leads to excessive penetration into the veneer and drying out at the surface, resulting in poor bonding at the interface. Conversely, adhesives with too high solid content are highly viscous and have poor penetration ability that also results in reduced bond strength due to the lack of effective mechanical interlocking. ${ }^{34,35,42}$ Hence, the observed reduced adhesive strength of formulations containing 15 and 35\% solids under soaked condition is likely attributable to the weaker bonding that arises from the differences in penetration depths of the adhesive from the surface of the veneer due to too low or too high viscosity of these formulations.

The formulation containing $20 \%$ solids performed similarly to those having 25 and $30 \%$ solids. As the development of formulations containing lower percentage of solids consumes lesser amounts of the components of the formulation, the formulations with lesser amount of solids have economical benefits over those containing higher amount of solids. Hence, the formulation containing $20 \%$ solids was considered for investigating the effect of other parameters on adhesive strength.

3.3.3. Effect of Et-peptides : PAE resin ratio. The extent of polymer-polymer interactions and/or crosslinking influences the interplay between the molecular weight of polymers and 
Table 6 Mode of failure of plywood specimens bonded with adhesive formulation developed by varying the ratio of Et-peptides and PAE resin. For each formulation, six test specimens were examined

\begin{tabular}{lll}
\hline Wt $\%$ of PAE resin (dry basis) & Dry samples & Soaked samples \\
\hline 0 & Adhesive failure $=100 \%$ & $100 \%$ of samples delaminated when soaked in water \\
6 & Adhesive failure $=100 \%$ & $100 \%$ of samples delaminated when soaked in water \\
11 & Fibre pulled out $=67 \%$ & Adhesive failure $=100 \%$ \\
& Adhesive failure $=33 \%$ & Adhesive failure $=83 \%$ \\
22 & Cohesive wood failure $=50 \%$ & Fibre pulled out $=17 \%$ \\
33 & Fibre pulled out $=50 \%$ & Fibre pulled out $=50 \%$ \\
& Cohesive wood failure $=83 \%$ & Adhesive failure $=50 \%$ \\
44 & Fibre pulled out $=17 \%$ & Cohesive wood failure $=83 \%$ \\
& Cohesive wood failure $=100 \%$ & Fibre pulled out $=17 \%$ \\
55 & Cohesive wood failure $=83 \%$
\end{tabular}

adhesive strength by affecting both bulk property and surface interactions of the adhesive system. ${ }^{37}$ Consequently, varying the peptides : PAE resin ratio in adhesive formulations is expected to significantly affect the adhesive strength by influencing the extent of polymer crosslinking and bulk property of the adhesive system. Hence, we investigated the effect of varying the weight percentage of crosslinking agent (PAE resin) of this formulation on lap shear strength of resulting plywood specimens.

The adhesive strength of Et-peptides-PAE resin system was significantly affected by the amount of crosslinking agent added in the formulation (Fig. 4). Both dry and soaked shear strengths of plywood specimens bonded with this adhesive improved progressively with increasing proportion of PAE resin, and

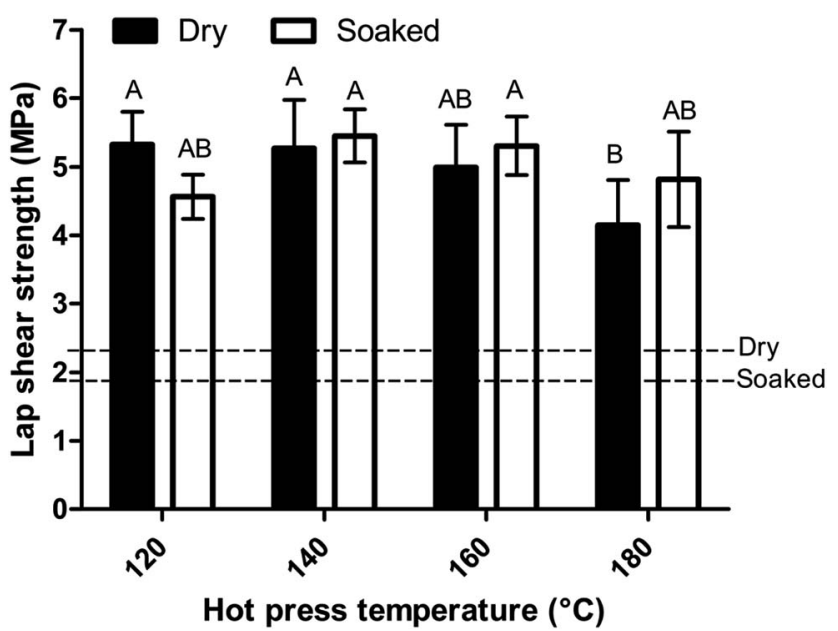

Fig. 5 Effect of hot pressing temperature of specimen preparation on lap shear strength of plywood specimens bonded with Et-peptidesPAE adhesives. The solid content of the adhesive formulation was $20 \%$ and the mixing time was 120 minutes. Specimens were hot pressed at 3.5 $\mathrm{MPa}$ for five minutes. Error bars indicate standard deviation of six plywood specimen measurements. Means that do not share a letter are significantly different (Tukey, 95\% confidence level). The minimum shear strength requirements as specified by ASTM D4690 are shown: 2.344 MPa for dry shear strength; and $1.93 \mathrm{MPa}$ for soaked shear strength. levelled off after reaching $44 \mathrm{wt} \%$ of PAE resin in the formulation. This infers that effective crosslinking of Et-peptides and PAE resin was achieved when they were reacted in the proportion of $44: 56$ (PAE resin : Et-peptides) by weight. Even though the formulation containing 33\% PAE resin had appreciable dry shear strength, this formulation produced test specimens that underwent either adhesive failure or shallow wood failure under soaked condition (Table 6). This is most likely due to the reason that the formulation consisting of $33 \%$ PAE resin contains some unreacted peptides which were presumably washed off during the soaking test, resulting in significantly lower soaked shear strength as compared to those of the formulations having 44 and 55\% PAE resin. This is more obvious for formulations consisting of 6,11 and $22 \%$ PAE resin. Conversely, further addition of PAE resin after $44 \%$ did not cause a notable increase in the adhesive strength of the Et-peptides-PAE formulations as evident from the results of Fig. 4 and the failure mode of test specimens under dry and soaked conditions (Table 6). Further, it appears that the formulations consisting of 44 and $55 \%$ PAE resin have achieved the adhesive strength similar to the strength of wood. Hence, the levelling off of adhesive strength after $44 \%$ of PAE resin is most likely due to two reasons: (i) the strength of wood limits the strength of adhesive, and/or (ii) the extent of crosslinking did not increase significantly after $44 \mathrm{wt} \%$ of crosslinking agent.

The formulation containing 33\% PAE resin and 67\% Etpeptides contained $3.0 \mathrm{~g}$ PAE resin and $1.5 \mathrm{~g}$ Et-peptides (Table 1). Since the molecular weight of a repeating unit of PAE resin is $332.82 \mathrm{amu}$, this formulation contains $4.5 \mathrm{mmol}$ of azetidinium groups. From our estimation of carboxyl and amine groups, this formulation contains $3.7 \mathrm{mmol}$ of carboxyl groups and $1.3 \mathrm{mmol}$ of amine groups. Considering that some molecules of PAE resin undergo homo-crosslinking in the curing step, ${ }^{20,22}$ the number of azetidinium groups of PAE resin of this formulation might not be sufficient to fully crosslink Etpeptides. The $44: 56$ formulation, on the other hand, contains $6.0 \mathrm{mmol}$ of azetidinium groups and $4.15 \mathrm{mmol}$ of carboxyl and amine groups. As the number of mmol of azetidinium groups of this formulation are more than the number of mmol of reacting groups contributed by Et-peptides, it seems reasonable that 
Table 7 Mode of failure of plywood specimens bonded with Et-peptides-PAE resin adhesives hot pressed at different temperatures. For each formulation, six test specimens were examined

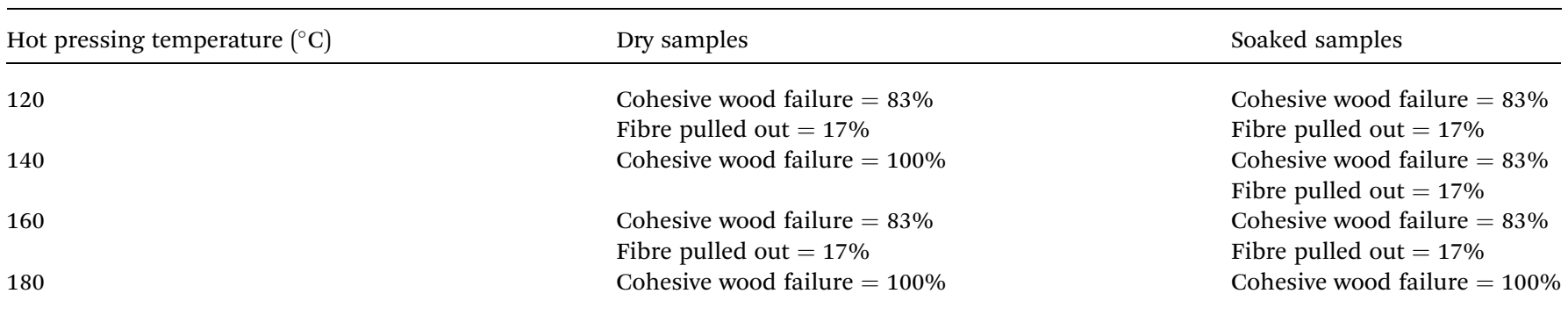

sufficient crosslinking of peptides has been achieved in the formulation containing $44 \mathrm{wt} \%$ of crosslinking agent.

Considering the ASTM specification requirements, the formulations containing 22 to $55 \mathrm{wt} \%$ PAE resin safely passed the requirements of UF type of wood adhesive resins for both dry as well as soaked conditions. Analysis of results of Fig. 4 further indicates that the formulation consisting of $44 \% \mathrm{PAE}$ resin has attained sufficient crosslinking, and the shear strengths (both dry and soaked) of formulations containing higher amount of PAE resin are not significantly different from this formulation. Hence, the formulation consisting of $44 \% \mathrm{PAE}$ resin and $56 \%$ peptides was considered for further investigations.

3.3.4. Effect of curing conditions. In the curing step, the adhesive turns to a thermosetting resin and solidifies through the generation of more crosslinks and formation of three dimensional networks of polymer chains. When curing occurs under suboptimal conditions, the adhesive will lack cohesive strength, and the cohesive strength may be the limiting factor in bond strengths. ${ }^{36}$ Hot pressing temperature and pressure are two important parameters that significantly affect curing of protein-based adhesives. Hence, the effects of hot pressing temperature and pressure on adhesive strength of Et-peptidesPAE resin adhesive were investigated in order to have insight into optimal curing conditions of this system.

3.3.4.1. Effect of hot pressing temperature on adhesive strength. The lap shear strength values of specimens pressed in the range of 120 to $180{ }^{\circ} \mathrm{C}$ indicated that hot pressing temperatures in this range had no remarkable effect on lap shear strength of plywood specimens (Fig. 5). Even though the lap shear strength values of specimens pressed at $180{ }^{\circ} \mathrm{C}$ and analyzed under dry conditions were significantly lower than those treated at 120 and $140{ }^{\circ} \mathrm{C}$, all of the specimens pressed at $180{ }^{\circ} \mathrm{C}$ underwent cohesive wood failure with deep wood fracture from the bondline (Table 7 ). This indicates that the drop in dry shear strength of specimens pressed at $180{ }^{\circ} \mathrm{C}$ is attributable to the effect of temperature on veneers rather than on the strength of adhesive bonding. In fact, thermal treatment of wood at higher temperature reportedly results in decreased mechanical properties and more brittle structure. ${ }^{4-46}$ Whereas the mechanical strength of poplar veneer was not significantly affected on heating at a temperature less than $170{ }^{\circ} \mathrm{C}$, a treatment temperature of $190{ }^{\circ} \mathrm{C}$, on the other hand, decreased the mechanical strength of veneers by more than $10 \% .{ }^{47}$ A significant reduction on mechanical properties was also observed for laminated lumber veneers developed from poplar veneer treated at $180{ }^{\circ} \mathrm{C}^{46}$

3.3.4.2. Effect of hot pressing pressure on adhesive strength. In plywood manufacturing, pressing of glued veneer sheets helps in (i) promoting effective mechanical interlocking by forcing adhesive to penetrate into the wood structure, and (ii) enhancing the interactions between adhesive molecules and the wood-surface by bringing the active sites of adhesive and substrate together. The latter is achieved through the formation of covalent linkages as well as secondary interactions. ${ }^{35}$ For soy protein-based wood adhesive, Cheng and Sun found that hot pressing pressure was one of the most significant factors for developing strong bonding, and the best results were obtained when the specimens were pressed using 4.5 MPa pressure. ${ }^{42}$ For our adhesive system, pressing pressure also had remarkable effect on adhesive strength (Fig. 6). Adhesive failure of test specimens was observed when the specimens were pressed below 2.5 MPa pressure in curing step (Table 8). This indicates that the pressing pressure below

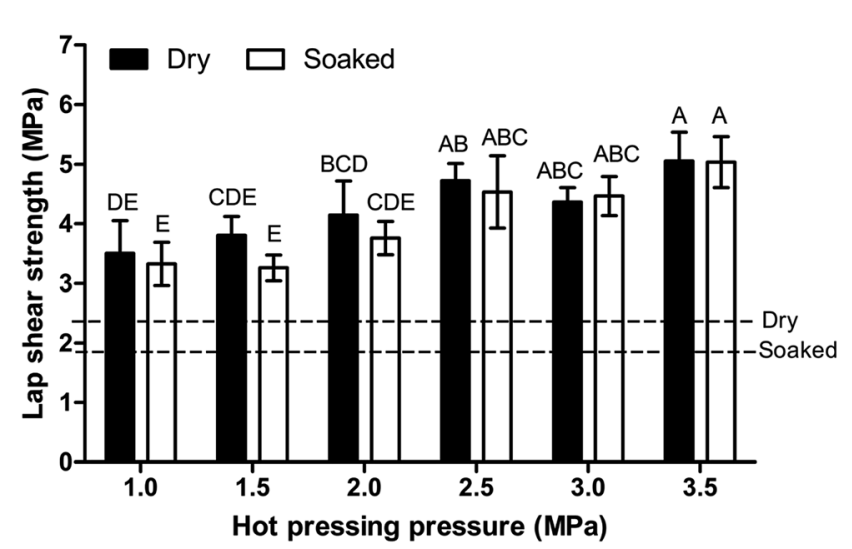

Fig. 6 Effect of hot pressing pressure of specimen preparation on lap shear strength of plywood specimens bonded with Et-peptides-PAE adhesives. The solid content of adhesive formulation was $20 \%$ and the mixing time was 120 minutes. Specimens were hot pressed at $120^{\circ} \mathrm{C}$ for five minutes. Error bars indicate standard deviation of six plywood specimen measurements. Means that do not share a letter are significantly different (Tukey, 95\% confidence level). The minimum shear strength requirements as specified by ASTM D4690 are shown: 2.344 MPa for dry shear strength; and $1.93 \mathrm{MPa}$ for soaked shear strength. 
Table 8 Mode of failure of plywood specimens bonded with Et-peptides-PAE resin adhesives hot pressed at different pressures. For each formulation, six test specimens were examined

\begin{tabular}{|c|c|c|}
\hline Hot pressing pressure (MPa) & Dry samples & Soaked samples \\
\hline \multirow[t]{2}{*}{1.0} & Fibre pulled out $=50 \%$ & Fibre pulled out $=17 \%$ \\
\hline & Adhesive failure $=50 \%$ & Adhesive failure $=83 \%$ \\
\hline & Adhesive failure $=33 \%$ & Adhesive failure $=83 \%$ \\
\hline \multirow[t]{2}{*}{2.0} & Cohesive wood failure $=17 \%$ & Fibre pulled out $=83 \%$ \\
\hline & Fibre pulled out $=66 \%$ & Adhesive failure $=17 \%$ \\
\hline & Fibre pulled out $=50 \%$ & Fibre pulled out $=50 \%$ \\
\hline \multirow[t]{2}{*}{3.0} & Cohesive wood failure $=83 \%$ & Cohesive wood failure $=83 \%$ \\
\hline & Fibre pulled out $=17 \%$ & Fibre pulled out $=17 \%$ \\
\hline \multirow[t]{2}{*}{3.5} & Cohesive wood failure $=83 \%$ & Cohesive wood failure $=83 \%$ \\
\hline & Fibre pulled out $=17 \%$ & Fibre pulled out $=17 \%$ \\
\hline
\end{tabular}

2.5 $\mathrm{MPa}$ is suboptimal for this adhesive system and the adhesive lacks cohesive strength.

\subsection{Effect of chemical modification on adhesive strength and water resistance property}

From the study on the effect of different parameters on adhesive strength of Et-peptides-PAE resin, it follows that the best suited conditions for using this adhesive system as plywood adhesive are: $20 \%$ solids with a peptides : PAE resin ratio of $56: 44$, reacted for 120 minutes prior to coating, and the specimens pressed at a minimum of $120{ }^{\circ} \mathrm{C}$ and $2.5 \mathrm{MPa}$ pressure for 5 minutes. These were the suitable conditions found for unmodified peptides as well. ${ }^{26}$ Hence, we evaluated the performance of unmodified as well as Et-peptides and a commercial phenol-formaldehyde (PF) resin under these conditions of adhesive formulation and specimen preparation. The Etpeptides yielded the plywood specimens that had statistically similar dry and soaked shear strengths to those of specimens bonded with PF resin (Fig. 7a). Even though the lap shear strength values of plywood specimens bonded with unmodified peptides under the specified conditions mentioned in Fig. 7 were statistically lower than those bonded with PF resin, the test specimens bonded with peptides-based formulations exhibited comparable bond strength (Fig. 7a) and mostly underwent cohesive wood failure. As the strength of veneer limits the strength of adhesive system in dry and soaked conditions, it is not very reliable to directly compare the strength property of unmodified peptides and Et-peptides-based formulations under dry and soaked conditions. Hence, we investigated the wet shear strength of adhesive formulations developed from Etpeptides as well as unmodified peptides (Fig. 7b). It is evident that Et-peptides-based formulations performed significantly better than the formulation containing unmodified peptides in wet strength analysis. The most obvious reason for this performance enhancement in wet shear strength is that esterification renders the highly hydrophilic carboxyl groups to less hydrophilic functions thereby increasing the water resistance property of the adhesive system. (a)
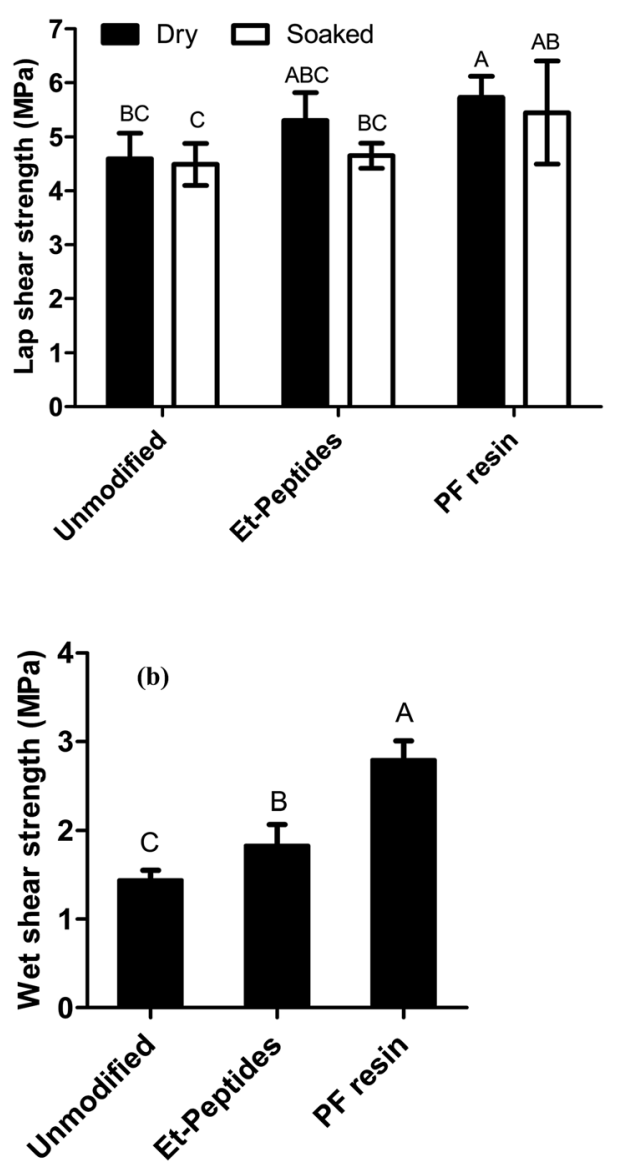

Fig. 7 Comparison of dry and soaked shear strengths (a) and wet shear strengths (b) of plywood specimens bonded with peptides-PAE-based adhesives and PF resin. The solid content of peptides-based adhesive formulations was $20 \%$ and the mixing time was 120 minutes. Specimens were hot pressed at $120{ }^{\circ} \mathrm{C}$ and $2.5 \mathrm{MPa}$ for five minutes. Error bars indicate standard deviation of six plywood specimen measurements. Means that do not share a letter are significantly different (Tukey, 95\% confidence level). 


\section{Conclusions}

Previously, we had reported on successful incorporation of hydrolysed protein fragments of SRM in adhesive formulations in combination with PAE resin as a crosslinking agent. Herein, we explored the effect of chemical modification of peptides on the water resistance property of the resulting adhesive formulations. The effects of various parameters associated with developing adhesive formulations and curing were examined. Under the investigated conditions, the formulation developed from ethyl ester derivative of peptides and PAE resin demonstrated similar performance to that of commercial phenol formaldehyde resin in dry and soaked shear strengths of plywood specimens. This formulation can be used as a plywood adhesive after reacting the components for 30 minutes at room temperature, and remains fully functional for 120 minutes with no significant difference in adhesive strength under dry as well as soaked conditions. This means that this formulation has a suitable pot life for plywood applications. The adhesive formulations containing as high as 78\% peptides met the ASTM D4690 requirements of both dry and soaked shear strengths for urea formaldehyde resin type of wood adhesive. Formulations containing 20 and $25 \%$ solids performed best on soaked shear strength. Whilst the performance of this adhesive system was not significantly affected by hot pressing temperature in the range of 120 to $180{ }^{\circ} \mathrm{C}$, hot pressing pressure exhibited significant impact on adhesive strength. In wet shear strength analysis of plywood specimens, the ethyl ester derivative demonstrated significant improvement over unmodified peptides. This research has demonstrated that chemical modification of peptides is a simple and reliable approach of improving water resistance property of adhesive formulations developed from hydrolyzed protein fragments.

\section{Conflicts of interest}

There are no conflicts to declare.

\section{Acknowledgements}

This research was possible due to the generous financial support from the Alberta Livestock and Meat Agency (ALMA), Alberta Innovates - Bio Solutions (AI Bio), Biorefining Conversions Network (BCN), Alberta Prion Research Institute (APRI), and Natural Science and Engineering Research Council of Canada (NSERC). The authors are grateful to Scanning Electron Microscope Lab, Department of Earth and Atmospheric Sciences, University of Alberta for their generous support in acquiring the SEM images.

\section{References}

1 D. L. Marti, R. J. Johnson and K. H. Mathews, Where's the (not) Meat? - Byproducts from Beef and Pork Production, LDPM-209-01, Economic Research Service, United States Department of Agriculture, Washington, DC, USA, 2011.
2 K. Jayathilakan, K. Sultana, K. Radhakrishna and A. S. Bawa, J. Food Sci. Technol., 2012, 49, 278-293.

3 C. Opio, P. Gerber, A. Mottet, A. Falcucci, G. Tempio, M. MacLeod, T. Vellinga, B. Henderson and H. Steinfeld, Greenhouse Gas Emissions from Ruminant Supply Chains - A Global Life Cycle Assessment, E-ISBN 978-92-5-107945-4, Food and Agriculture Organization of the United Nations (FAO), Rome, Italy, 2013.

4 I. H. Franke-Whittle and H. Insam, Crit. Rev. Microbiol., 2013, 39, 139-151.

5 K. Swisher, Prices are Down but Demand Remains Strong, Render Magazine, Placerville, CA, USA, 2016.

6 Enhanced Animal Health Protection from BSE - Specified Risk Materials (SRM), http:/www.inspection.gc.ca/ animals/terrestrial-animals/diseases/reportable/bse/srm/eng/ 1299870250278/1334278201780, accessed 09/20 2017.

7 Annex D: Specified Risk Materials, http:// www.inspection.gc.ca/food/meat-and-poultry-products/manualof-procedures/chapter-17/annex-d/eng/1369768468665/136976 8518427, accessed 06/10 2017.

8 Bovine Spongiform Encephalopathy, https://www.fda. gov/AnimalVeterinary/GuidanceComplianceEnforcement/ ComplianceEnforcement/BovineSpongiformEncephalopathy/ default.htm, accessed 09/20 2017.

9 Control of TSEs (Including BSE and Scrapie), https:// ec.europa.eu/food/safety/biosafety/food_borne_diseases/tse_ bse_en, accessed 09/20 2017.

10 FDA Announces Final Rule on Bovine Spongiform Encephalopathy, https://www.fda.gov/food/newsevents/ constituentupdates/ucm490542.htm, accessed 09/20 2017.

11 Informa Economics, An Economic and Environmental Assessment of Eliminating Specified Risk Materials and Cattle Mortalities from Existing Markets, 04-021ANPR-68, Informa Economics, Inc., McLean, VA, USA, 2004.

12 T. Mekonnen, P. Mussone, K. Alemaskin, L. Sopkow, J. Wolodko, P. Choi and D. Bressler, J. Mater. Chem. A, 2013, 1, 13186-13196.

13 T. Mekonnen, P. Mussone, N. El-Thaher, P. Y. K. Choi and D. C. Bressler, Macromol. Mater. Eng., 2013, 298, 1294-1303.

14 T. H. Mekonnen, P. G. Mussone, P. Choi and D. C. Bressler, Macromol. Mater. Eng., 2014, 299, 1003-1012.

15 T. H. Mekonnen, P. G. Mussone, P. Choi and D. C. Bressler, Macromol. Mater. Eng., 2015, 300, 198-209.

16 IARC, Working Group on the Evaluation of Risk to Humans, Formaldehyde, 2-Butoxyethanol and 1-tert-Butoxypropan-2-ol, Inter. Agency Res. Cancer, 2006, vol. 88, pp. 1-479.

17 Grand View Research, Wood Adhesives Market Analysis By Product (Urea-Formaldehyde, Melamine Urea, PhenolFormaldehyde, Isocyanate, Polyurethane, PVA, Soy-based), By Application (Flooring, Furniture, Doors \& Windows), And Segment Forecasts, 2014-2025, GVR-1-68038-307-2, Grand View Research, Inc., San Francisco, CA, USA, 2017.

18 USB, 2017 Soy Product Guide, United Soybean Board, Chesterfield, MO, USA, 2017.

19 B. B. Adhikari, P. Appadu, M. Chae and D. C. Bressler, in Biobased Wood Adhesives: Preparation, Characterization, and 
Testing, ed. Z. He, CRC Press, Boca Raton, FL, USA, 2017, pp. 1-56.

20 K. Li, S. Peshkova and X. Geng, J. Am. Oil Chem. Soc., 2004, 81, 487-491.

21 Y. Liu and K. Li, Int. J. Adhes. Adhes., 2007, 27, 59-67.

22 Z. Zhong, X. S. Sun and D. Wang, J. Appl. Polym. Sci., 2007, 103, 2261-2270.

23 T. Obokata, M. Yanagisawa and A. Isogai, J. Appl. Polym. Sci., 2005, 97, 2249-2255.

24 L. Wågberg and M. Björklund, Nord. Pulp Pap. Res. J., 1993, 8, 53-58.

25 H. H. Epsy, Tappi J., 1995, 78, 90-99.

26 B. B. Adhikari, P. Appadu, V. Kislitsin, M. Chae, P. Choi and D. C. Bressler, Polymers, 2016, 8, 285.

27 T. H. Mekonnen, P. G. Mussone, N. Stashko, P. Y. Choi and D. C. Bressler, Process Biochem., 2013, 48, 885-892.

28 H. Fraenkel-Conrat and H. S. Olcott, J. Biol. Chem., 1945, 161, 259-268.

29 H. Seki, H. Maruyama and Y. Shoji, Biochem. Eng. J., 2010, 51, 14-18.

30 C. Wang, J. Wu and G. M. Bernard, Ind. Crops Prod., 2014, 57, 124-131.

31 EPA, in Compilation of Air Pollutant Emission Factors AP-42, United States Environmental Protection Agency, Durham, NC, USA, 1995, p. 10.5-3.

32 N. Li, G. Qi, X. S. Sun, M. J. Stamm and D. Wang, J. Am. Oil Chem. Soc., 2012, 89, 897-908.

33 X. Mo and X. S. Sun, J. Adhes. Sci. Technol., 2013, 27, 20142026.
34 C. R. Frihart, in Handbook of Wood Chemistry and Wood Composites, ed. R. M. Rowell, CRC Press, Cleveland, USA, 2005, pp. 215-278.

35 C. R. Frihart and C. G. Hunt, in Wood Handbook - Wood as an Engineering Material, Forest Products Laboratory, Madison, WI, USA, 2010, pp. 1-24.

36 J. A. von Fraunhofer, Int. J. Dent., 2012, 2012, 1-8.

37 C. L. Jenkins, H. J. Meredith and J. Wilker, ACS Appl. Mater. Interfaces, 2013, 5, 5091-5096.

38 ASTM, Standard Specifications for Urea Formaldehyde Resin Adhesive. Designation D4690 - 12, 2012.

39 I. Khan and B. T. Poh, J. Appl. Polym. Sci., 2011, 120, 26412647.

40 S. S. Ali, X. Z. Tang, S. Alavi and J. Faubion, J. Agric. Food Chem., 2011, 59, 12384-12395.

41 I. Khan and B. T. Poh, J. Polym. Environ., 2012, 20, 132-141.

42 E. Cheng and X. Sun, J. Adhes. Sci. Technol., 2006, 20, 9971017.

43 V.-D. Troung, D. A. Clare, G. L. Catignani and H. E. Swaisgood, J. Agric. Food Chem., 2004, 52, 1170-1176.

44 Y. Kubojima, T. Okano and M. Ohta, J. Wood Sci., 2000, 46, 815.

45 J. L. Shi, D. Kocaefe and J. Zhang, Holz Roh-Werkst., 2007, 65, 255-259.

46 M. Nazerian and D. Ghalehno, J. Agric. Sci. Technol. A, 2011, 1, 1040-1045.

47 K. Murata, Y. Watanabe and T. Nakano, Materials, 2013, 6, 410-420. 